\title{
O USO DA PLATAFORMA YOUTUBE POR ACADÊMICOS DO ENSINO SUPERIOR
}

\section{ARTIGO ORIGINAL}

FRAGOSO, Emílio Lopes ${ }^{1}$

PIRES, Valéria de Albuquerque ${ }^{2}$

FRAGOSO, Emílio Lopes. PIRES, Valéria de Albuquerque. O uso da plataforma Youtube por acadêmicos do Ensino Superior. Revista Científica Multidisciplinar Núcleo do Conhecimento. Ano 05, Ed. 08, Vol. 08, pp. 54-71. Agosto de 2020. ISSN: 2448-0959, Link de acesso: https://www.nucleodoconhecimento.com.br/educacao/plataforma-youtube

\section{RESUMO}

A globalização trouxe mudanças significativas em todas as áreas da sociedade, inclusive no âmbito educacional. O surgimento das novas Tecnologias de Informação e Comunicação (TIC), advindas da evolução, modificou a maneira de se comunicar, estudar e aprender, trazendo mais conforto e agilidade às nossas vidas. A exemplo das mídias sociais, que já são bastante utilizadas no nosso cotidiano, mais especificamente a mídia social YouTube, que hoje é uma plataforma usada com frequência pelos alunos e boa parte dos professores em sala de aula, em busca de trazer aulas mais prazerosas, dinâmicas e motivação dos alunos em estudar, pois possui conteúdos diversos e o acesso gratuito. Dessa forma, esse trabalho tem como objetivo investigar como o uso da plataforma YouTube nas aulas, durante o ensino superior, contribui no processo ensino-aprendizagem, apontando qual a possibilidade de utilização desta ferramenta como recurso pedagógico. Nossa metodologia se deu

\footnotetext{
${ }^{1}$ Graduação em Licenciatura de Ciências Biológicas.

${ }^{2}$ Orientadora. Doutorado em Zoologia. Mestrado em Zoologia. Graduação em Biologia Modalidade Bacharelado.
} 
através do aplicativo Google Forms, foi criado um questionário semiestruturado sobre a percepção dos discentes, frente ao uso da plataforma YouTube. Foram entrevistados 94 participantes e obtivemos resultados satisfatórios, a pesquisa demonstrou que este é um excelente recurso pedagógico, que é bastante utilizado pelos estudantes, para estudar e fazer trabalhos acadêmicos. Os estudantes acham importante este uso, pois fica bem mais fácil aprender, memorizar, revisar e aprofundar melhor os estudos, e assim entendem super bem o conteúdo. Além disso, a maioria dos alunos opinou que essa assistência traz contribuições para suas aprendizagens, que já vivenciaram aulas com professores usando o Youtube, e que acham importante e gostam quando o docente utiliza vídeos durante as aulas. Os alunos também apoiam a utilidade desta e de outras novas tecnologias no processo de ensino-aprendizagem. Logo, evidenciou-se que o emprego de tecnologias na educação têm se mostrado muito eficiente e vêm se solidificando dentro do cenário educacional atual, potencializando a busca do conhecimento e o desenvolvimento educacional.

Palavras-chave: Mídia, tecnologia na educação, ensino, aprendizagem.

\section{INTRODUÇÃO}

Atualmente vivenciamos a era das tecnologias e modernizações, chamada era da globalização. Essa fase vem modificando o nosso cotidiano, com todos os avanços, recursos e diversos tipos de meio de comunicação que vem surgindo, trazendo mais conforto e agilidade às nossas vidas, bem como encurtando o tempo as distancias (SCHMITT, 2015).

As inovações tecnológicas e o surgimento de novos tipos de mídias consolidam-se como importantes estratégias para o desenvolvimento educacional. A acelerada evolução das tecnologias, a exemplo da internet, tem proporcionado um rápido e fácil acesso à informação e ao conhecimento, como também, um acúmulo diversificado dessas informações (PEREIRA; SOUZA; PEIXINHO, 2012). 
Numa perspectiva de promover uma educação de qualidade com um aprendizado mais proveitoso e significativo é comum que a discussão sobre a utilidade de novas tecnologias no meio pedagógico apareça. Inserir novos recursos às antigas práticas e métodos tradicionais de sala de aula parece facilitar o processo ensino aprendizagem, ainda mais, em um período em que as novas tecnologias são costumeiras, tanto dentro como fora da escola (SÉRIO; KAWAMURA,2014).

Hoje, as mídias estão influenciando a forma de comunicação e educação das pessoas, o uso de tais ferramentas nas salas de aulas traz diversos benefícios. Já se tornou necessário modernizar o ambiente escolar com inserção de práticas mais dinâmicas, os vídeos são de grande valia nesse processo, trazendo novas posturas nas práticas docentes, com professores sendo mediadores do conhecimento e motivando os discentes a serem protagonistas de sua aprendizagem (MYCHALEYCO, 2015).

É fundamental aproveitar estes recursos em prol do aprendizado e conhecimento, pois, o discente é um cidadão totalmente incorporado ao mundo digital e virtual, podemos notabilizar tal fato pela disseminação de imagens e vídeos na internet, como, por exemplo, no site YouTube, onde a cada minuto são postados 300 horas de vídeos, bem como, recebe 4 bilhões de visualizações diárias (MYCHALEYKO, 2015).

A utilização dessas mídias de vídeo no Ensino não é novidade, com a propagação da internet tornou-se facilitado a distribuição e utilização desses vídeos. O YouTube já é um site de compartilhamento de vídeo bastante popular. Estatísticas da própria plataforma mostram que mais de 1 bilhão de usuários únicos acessam o site todos os meses e mais de 6 bilhões de horas de vídeos são assistidas por mês na página YouTube, ou seja, quase uma hora para cada pessoa no mundo (SÉRIO; KAWAMURA, 2014).

Na plataforma do YouTube, os alunos têm a possibilidade de fazer o download, ou seja, baixar os vídeos para o computador ou celular por meio de assistência de aplicativos e outras mídias e poderão assistir os vídeos a qualquer momento e horário de acordo com sua preferência, e ainda, de maneira prática (SILVA, 2009). Assim 
sendo, o YouTube poderá auxiliar o processo de formação e apropriação do conhecimento, para também no âmbito educacional permitir a interatividade e a troca de experiências, facilitando no ensino superior, que novos conhecimentos venham a reforçar os que já foram adquiridos, pelo fato, também, da possibilidade de voltar o vídeo e assistir quantas vezes for necessário (SILVA, 2009).

O uso das inovações tecnológicas possibilita o desenvolvimento do conhecimento dos alunos. Segundo uma pesquisa feita sobre o uso das tecnologias de informação e comunicação nas escolas brasileiras, divulgada pelo Comitê Gestor da Internet no Brasil (CGI.br), 73\% dos professores já incorporaram o computador e/ou a internet como ferramenta pedagógica.

Neste sentido, este trabalho tem como objetivo investigar como o uso da plataforma YouTube, durante o ensino superior, contribuem no processo ensino-aprendizagem, apontando qual a possibilidade de utilização dessa ferramenta como recurso pedagógico.

\section{MATERIAL E MÉTODOS}

\section{1 ÁREA DE ESTUDO}

Esta pesquisa foi direcionada preferencialmente à discentes regularmente inseridos em instituições de ensino superior. A pesquisa foi feita $100 \%$ Online por meio de um Link que direcionava automaticamente para o questionário da pesquisa e foi distribuído entre instituições públicas e privadas da região metropolitana de Belém/PA.

\subsection{COLETA DE DADOS}

Por se tratar de uma pesquisa pública e feita com alunos maiores de idade e sem qualquer identificação pessoal do participante, não houve necessidade de submissão para análise do comitê de ética, como previsto na Resolução 466/2012 do Conselho Nacional de Ética em Pesquisa (CONEP). Foi criado um questionário semiestruturado em um aplicativo do Google chamado Google Forms, este aplicativo norteou a nossa 
pesquisa, tivemos a oportunidade de divulgar e coletar acerca do ponto de vista e concepções dos alunos participantes, sobre a utilização do YouTube no ensino superior, e, ainda, foi possível elaborar nosso próprio formulário, com perguntas bem adequadas ao nosso objetivo. O questionário foi compartilhado através do aplicativo de mensagens (Whatsapp), para que o público alvo pudesse participar. O questionário online ficou disponível para resposta durante diversos dias até completar o número de 94 participantes, número considerado suficiente para alcançar nosso objetivo de trabalho.

\subsection{ANÁLISE DE DADOS}

Após a coleta dos questionários, estes foram baixados em formato Excel e analisados quali-quantitativamente, foram formados gráficos e tabelas para análise e discussão.

\section{RESULTADOS}

Analisando os dados obtidos constatou-se que tivemos participantes de diferentes faixas etárias, desde jovens a partir de 18 anos até adultos de 53 anos e que a média de idade destes participantes foram de 23 anos. A pesquisa obteve 94 alunos, sendo 59 mulheres (62,6\%), correspondendo à maioria, e 35 homens (37,4\%). Entre os integrantes do estudo foi observado que a maioria pertence à rede de ensino particular, equivalendo a $85,1 \%$, e apenas $15,9 \%$ de rede de ensino público.

Um ponto relevante observado é o fato de que $96,8 \%$ dos alunos possuem Internet em suas residências, sendo assim, a grande maioria. E, quando questionados sobre se já utilizaram a plataforma YouTube durante o período de faculdade, para fazer trabalho ou estudar, 93 alunos responderam que $\operatorname{sim}(99 \%)$, e apenas 1 aluno (1\%), respondeu que nunca a utilizou. (Figura 1) 
Figura 1: Resposta em percentual se os alunos já usaram o YouTube para fazer trabalho ou estudar.

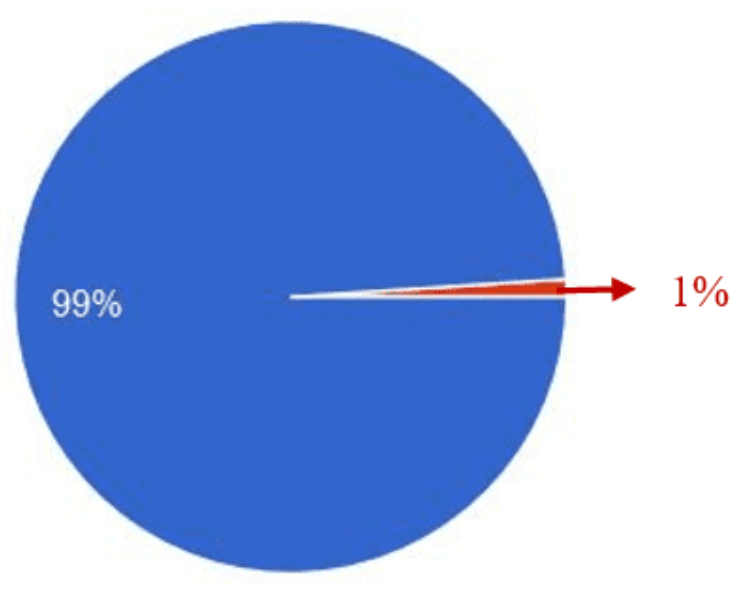

Fonte: Autores (2020)

Quando questionados sobre o local de onde mais acessam o YouTube para o estudo, a maioria respondeu de suas residências $(92,6 \%)$ ou da faculdade $(24,5 \%)$. (Figura 2)

Figura 2: Resposta em percentual do local de onde os participantes mais acessam o YouTube para estudar.

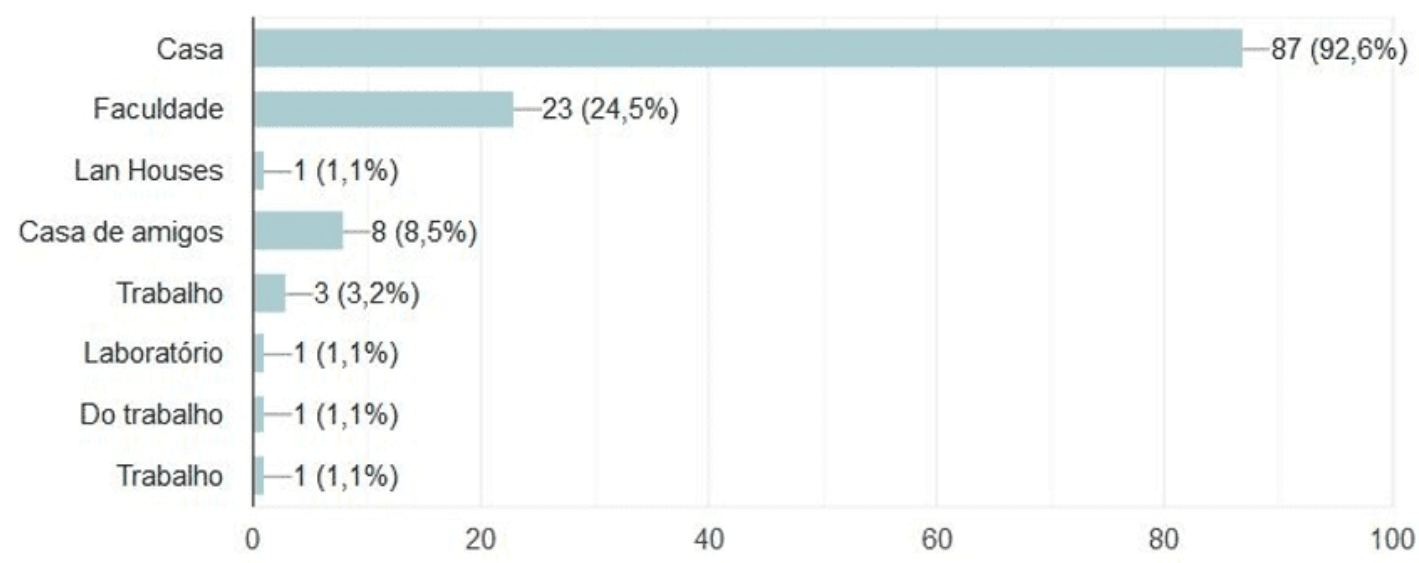

Fonte: Autores (2020) 
Agora se tratando de qual dispositivo os alunos conectam a plataforma YouTube, para o estudo, $83 \%$ afirmaram que o celular é o principal dispositivo. Outros responderam que utilizam mais o notebook (45,7\%) e o computador de mesa (30,9\%). (Figura 3 )

Figura 3: Resposta em percentual dos dispositivos mais utilizados no acesso do YouTube para estudar.

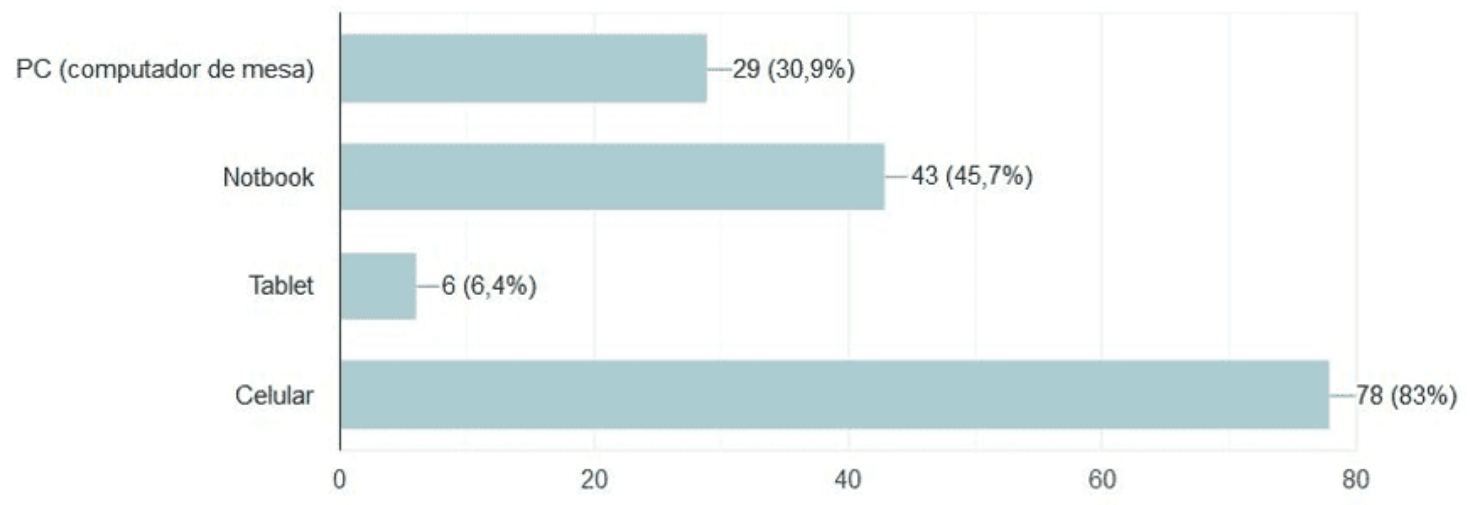

Fonte: Autores (2020)

Outro ponto interessante é o fato de que os alunos quando indagados sobre a importância de se utilizar o YouTube com finalidade de estudo e trabalho, 92,6\% responderam que sim, acham importante, e apenas uma minoria não acham interessante este uso. (Figura 4)

Figura 4: Resposta em percentual se acham importante utilizar o YouTube com finalidade de estudo e trabalho acadêmico.

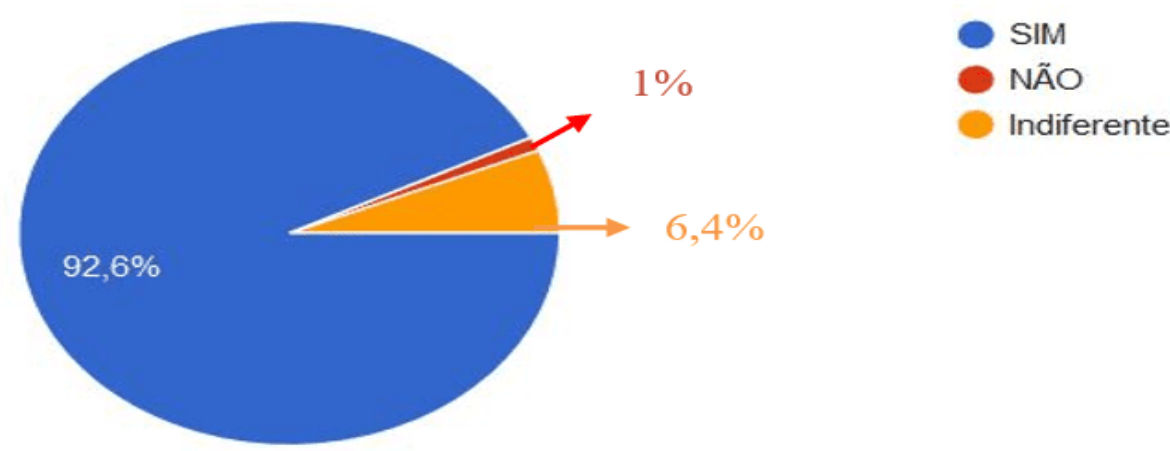

Fonte: Autores (2020) 
Ainda sobre a importância da utilização do YouTube para estudar ou fazer trabalhos acadêmicos, muitos opinaram positivamente em relação a ferramenta. Frente às concepções dos alunos alguns responderam que acham muito importante, porque aprendem de maneira diferente. Opinaram também que: A visualização de vídeos ou aulas online no site YouTube estimula mais o aprendizado pelo fato de ser uma plataforma gratuita, onde podem ter acesso a uma enorme quantidade e variabilidade de conteúdos e informações, locais e até globais, além de ser fácil o acesso e de maneira bem prática. Outros declararam ser interessante o uso devido ser possível assistir várias vezes os vídeos e assim fica bem mais fácil de aprender, memorizar, revisar e aprofundar melhor os estudos.

Com isso, nesta pesquisa, foi proposto um questionamento acerca do entendimento nas aulas. Perguntou-se, se com o auxílio do YouTube estes alunos entendem super bem o conteúdo, se entendem mais ou menos ou se não entendem. Obtivemos que: $81,4 \%$ afirmaram que com os vídeos durante as aulas entendem super bem o conteúdo.

Ainda tivemos a confirmação que a grande maioria dos alunos (90,4\%), acham relevante e gostam quando o professor utiliza vídeos durante as aulas. Do total dos acadêmicos participantes deste estudo, 77,3\% afirmaram que já vivenciaram aulas com professores utilizando a plataforma YouTube, como recurso pedagógico. (Figura 4)

Figura 4: Resposta em percentual dos que acham relevante e gostam quando o professor utiliza a plataforma YouTube durante as aulas.

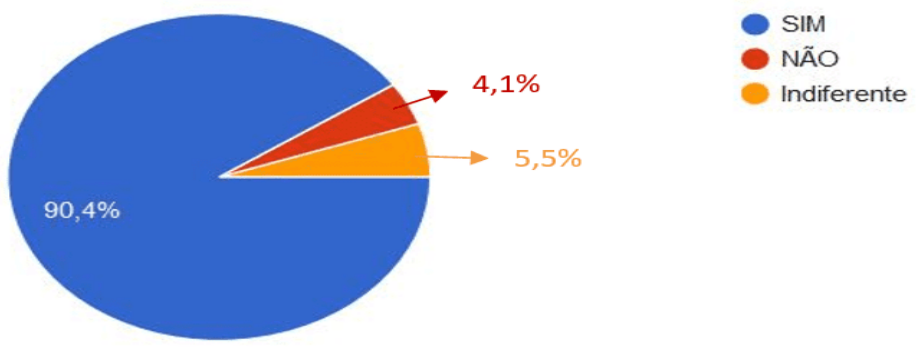


Fonte: Autores (2020)

Outra análise importante foi acerca da contribuição da plataforma YouTube. 95,7\% dos discentes afirmaram que este recurso contribui para a sua aprendizagem e uma pequena parte deles opinou que não contribui ou que é indiferente. Em destaque, também, foi apontado à finalidade da utilização deste recurso. $41,5 \%$ desses estudantes mencionaram que usufruem deste meio para revisar um assunto e outros 40,4\% para aprofundar mais o conteúdo estudado. (Figura 5) e (Figura 6)

Figura 5: Resposta em percentual se o uso do YouTube contribui para a aprendizagem dos discentes.

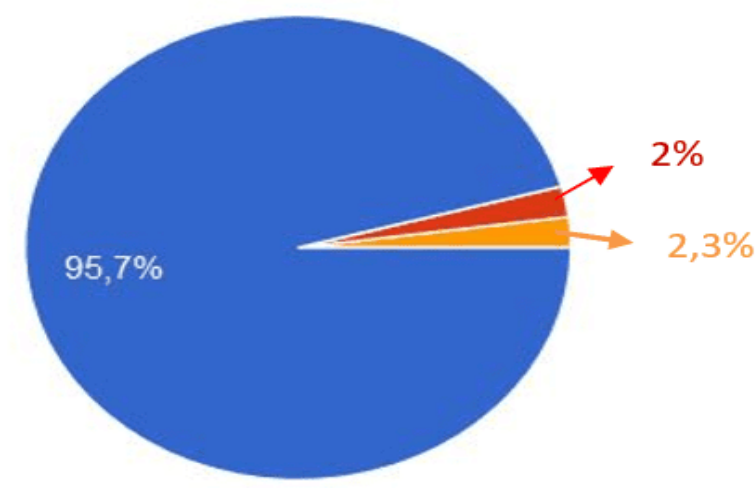

Fonte: Autores (2020)

Figura 6: Resposta em percentual sobre qual a finalidade do uso do YouTube.

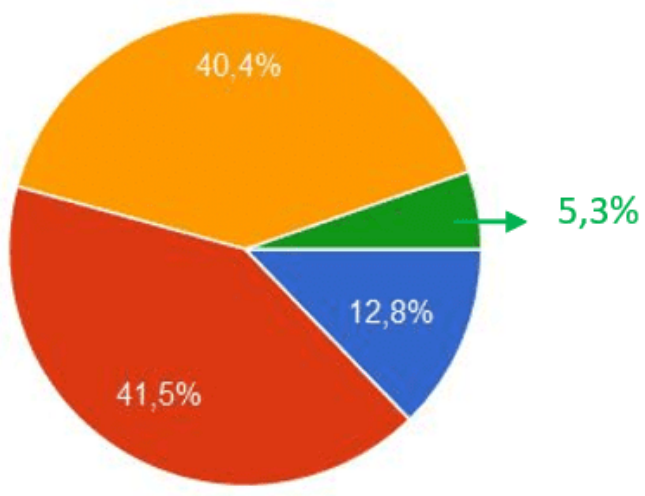

Fonte: Autores (2020) 
Os acadêmicos quando interrogados sobre qual nota atribuiria ao fator da colaboração do YouTube ao seu aprendizado, nota de 1 a 5 para a sua satisfação, obtivemos resultados bem positivos. (Figura 7 )

Figura 7: Resposta em percentual a satisfação pela colaboração do YouTube ao aprendizado.

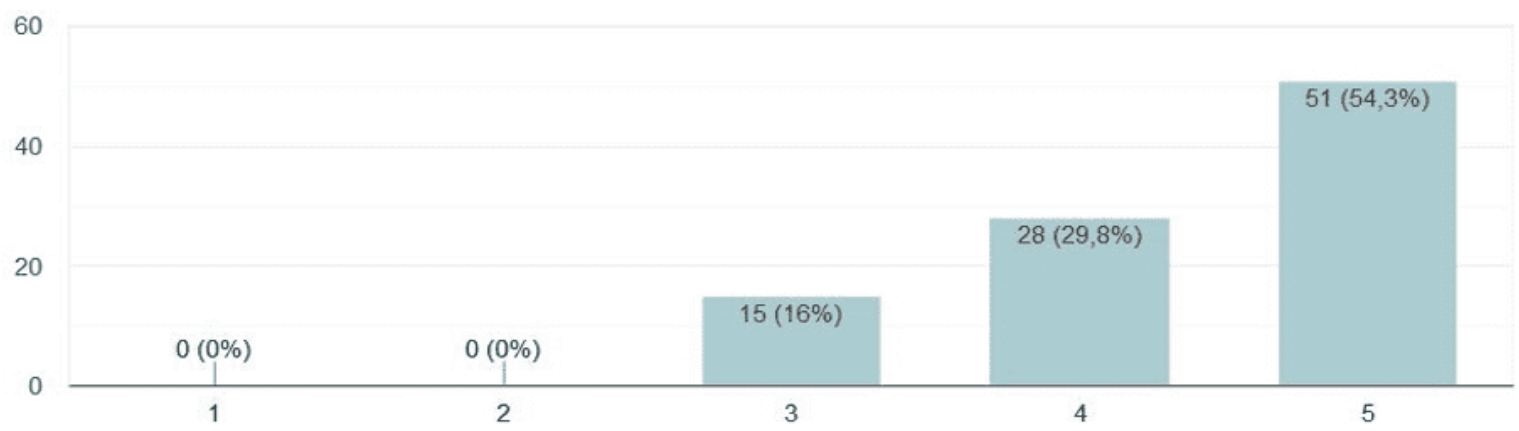

Fonte: Autores (2020)

Sobre o ponto de vista dos educandos se concordam com a utilização das novas tecnologias no processo de ensino-aprendizagem, nossa análise obteve que 79,8\% são favoráveis e concordam totalmente com o uso dessas inovações e uma menor parcela dos alunos concordam parcialmente $19,1 \%$, ou discordam do uso. (Figura 8)

Figura 8: Resposta em percentual se concordam com o emprego das novas tecnologias no processo de ensino-aprendizagem.

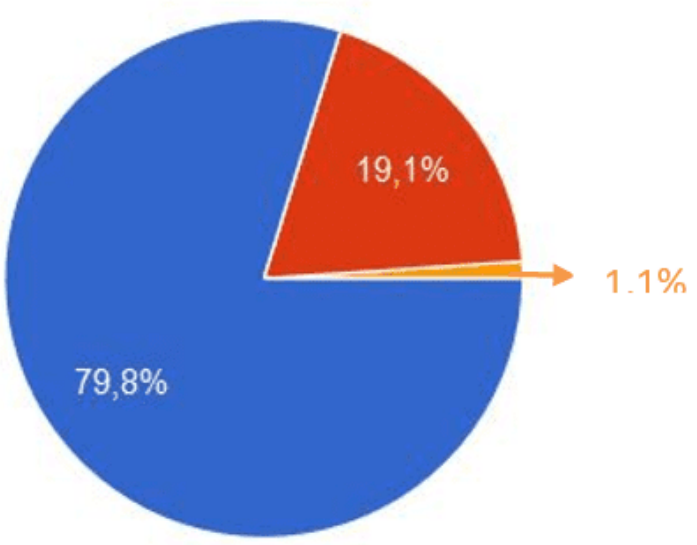

Concordo totalmente

Concordo Parcialmente

Discordo totalmente

Fonte: Autores (2020)

RC: 58842

Disponível em: https://www.nucleodoconhecimento.com.br/educacao/plataforma-youtube 


\section{DISCUSSÃO}

Depois de analisar os dados da pesquisa, percebeu-se que os estudantes consideram o uso da plataforma YouTube importante no processo de ensino-aprendizagem, e que a maior parte dos discentes utiliza este recurso como ferramenta pedagógica. Neste trabalho, a grande maioria das respostas comprova que esta ferramenta é bastante utilizada para estudo e trabalho acadêmico.

Ficou evidente no estudo que o YouTube se diferencia das instituições tradicionais de ensino ao apresentar um conteúdo apresentado de forma objetiva, com linguagem acessível, que facilita a compreensão dos alunos. A plataforma YouTube traz uma aprendizagem mais ativa, o aprendizado por meio de sons e imagens permite uma melhor assimilação das informações, uma melhor concentração, novas interações sociais e dinamismo nas aulas, resultando em elogios na maneira como as aulas são apresentadas em vídeos (PECHANSKY, 2016).

Da mesma maneira Almeida (2015) menciona que "a utilização do YouTube como ferramenta educacional midiática, atrai atenção dos alunos devido a sua fluidez de sons e imagens que captam o interesse do aluno, auxiliando na aquisição de saberes" (p. 11). Essa plataforma tem tido uma inserção social cada vez maior e vem cada dia mais contribuindo no processo educacional, servem de apoio para provocar debates e discussões em sala de aula, além de despertarem o interesse no conteúdo abordado e motivarem os discentes à investigação de novos temas, nas aulas. (ALMEIDA, 2015).

Notou-se, pelos dados coletados, que o local de onde os alunos mais acessam o site Youtube para estudar, são suas residências (92,6\%), e o dispositivo mais utilizado para tal acesso foi o aparelho celular (83\%), com isso é possível afirmar a familiaridade dos participantes com a tecnologia, o que indica uma tendência à portabilidade, à mobilidade e a facilidade do manuseio do aparelho, presentes no dia a dia. Um dos fatores que justificam esses percentuais citados foi à popularização do aparelho celular, no mundo globalizado em que vivemos. Hoje, com a facilidade de compras e com preços acessíveis é bem fácil possuir um celular, e também, pela propagação da 
internet no Brasil. Segundo uma pesquisa feita sobre pessoas conectadas na internet, divulgada pelo Comitê Gestor da Internet no Brasil (CGI.br), 70\% dos Brasileiros possuem internet, e o celular é o meio de acesso para $97 \%$ dos usuários (HIGA, 2018).

Quando falamos das análises sobre a importância de se utilizar o YouTube para estudo e trabalho acadêmico, foi obtido uma porcentagem bem significativa de aceitação e confirmação dessa importância, pois $92,6 \%$ dos discentes responderam achar importante. Pode-se compreender essa relevância, visto que os estudantes já estão familiarizados com este tipo de mídia social, pois buscam ferramentas atuais e acessíveis que possibilitem o processo de ensino-aprendizagem, e permita que esses alunos busquem de forma construtiva e autônoma o conhecimento (PEREIRA, 2018).

Um ponto interessante foi quando $90,4 \%$ dos acadêmicos participantes desse estudo, responderam que acham relevante e gostam quando o professor utiliza o YouTube durante as aulas. Hoje, grande parte dos professores já utiliza ou já utilizou material audiovisual em aula ou trabalhos para os alunos, permitindo também o uso dessa ferramenta pelo discente, fato vivenciado por $77,3 \%$ dos discentes interrogados. Esse meio educacional é de grande importância, pois permite que esse lecionando construa seu próprio conceito, seu conhecimento e estimula o aprendizado pela pesquisa, ajudando a formar um sujeito crítico, com autonomia, atuante na sociedade em que vive (MYCHALEYKO, 2015). É necessário explorar a capacidade que o vídeo tem de ir além do presencial, de mexer com outras formas de linguagens, de trazer outras realidades para mais próximo do estudante, atingindo os possíveis ganhos com esse recurso (KAMERS, 2013).

A utilidade dessas modernizações na educação tem se mostrado muito eficiente e vem se solidificando dentro do cenário educacional, essas inovações implicam em uma nova forma de pensar, agir e aprender. Vale lembrar que essas ferramentas tecnológicas não substituem o professor, pois ele é visto como mediador, ou seja, o que leva os alunos a conhecer e a interagir através dessas novas tecnologias existentes, ajudando na melhoria e qualidade da educação (SILVA, 2018). 
O YouTube nada mais é do que uma oportunidade de incentivar processos de autoria e coautoria, em que o professor e aluno desenvolvem projetos juntos, e assim, passam a se desenvolver e ter novos conceitos, além de que, melhoram consideravelmente os seus relacionamentos interpessoais (KAMERS, 2013).

Quando referirmos acerca da contribuição do YouTube para o aprendizado, 95,7\% confirmaram que contribui. Atualmente, a qualidade de ensino está diretamente relacionada ao uso de mídias no ambiente educacional, pois proporciona aulas com metodologias inovadoras que despertam o interesse do educando, assim contribuindo para resultados significantes no processo de aprendizagem (MYCHALEYKO, 2015). Os alunos são estimulados para aprendizagem pela linguagem atraente desses novos meios tecnológicos, que são capazes de aproximá-los o máximo possível da realidade, transformando os conteúdos em vivências, e, provavelmente, em vista disso, muitos utilizam esses meios para introduzir e revisar os assuntos, estudar assunto não visto em aula e outros para aprofundar mais os conteúdos estudados (SOUSA; LACERDA; LIMA, 2018).

Os docentes, se tratando de melhorias e qualidade de ensino, necessitam sempre estarem se aprimorando e se aperfeiçoando às novas propostas pedagógicas, sempre sabendo lidar com a dinamização do ensino. Os professores devem ter novas práticas educativas, porém necessitam de um tempo para conhecer e aprender a utilizar as ferramentas tecnológicas presentes nas escolas e faculdades, tem que estarem cada vez mais aptos e competentes a utilizarem as tecnologias em favor da educação (ALMEIDA, 2015).

Devemos ter em vista que: "ensinar é, por excelência, uma atividade que envolve elementos teóricos e metodológicos, e entendê-la como uma atividade indeterminada e influenciada por múltiplos fatores é essencial" (SOUSA; LACERDA; LIMA, 2018, p.16). Presentemente, se ressalta a necessidade de investimento na qualificação da educação, com intuito de superar os desafios e o avanço acelerado da ciência e tecnologia, da globalização. O processo ensino-aprendizagem deve ser dinâmico, bilateral, coletivo, é fundamental que sistematize parcerias entre o professor e os 
alunos e dos alunos entre si, pois, quando se possui um espírito ascendente e atitudes inovadoras, as atividades se tornam executáveis (SOUSA; LACERDA; LIMA, 2018).

Ainda, cabe ressaltar, que a aquisição da informação, dos dados, conhecimento, não dependerá apenas do professor, aprender depende também do aluno. As tecnologias podem trazer hoje dados, imagens, resumos de forma rápida e atrativa, mas o discente precisa estar preparado, maduro, para introduzir emocionalmente, de forma vivencial o real significado que a informação tem para ele, "Enquanto a informação não fizer parte do contexto pessoal-intelectual e emocional não se tornará verdadeiramente significativa, não será aprendida verdadeiramente" (MORAN, 1999, p.1).

O YouTube é um ótimo auxílio pedagógico, como recurso para potencializar as estratégias de ensino, é pertinente já que é utilizada por grande parte dos estudantes de todos os níveis educacionais. Atualmente a plataforma é a segunda maior rede social do mundo ficando atrás somente do Facebook, existente em 130 países e possui 200 milhões de canais ativos. Dentre os canais disponíveis foi criada uma plataforma direcionada para vídeos educativos, com 90 canais educacionais (MELONIO; FAÇANHA, 2018).

Cabe destacar, que os educadores devem analisar quais os conteúdos, linguagem, imagem que são expostos nos diversos canais para que a ferramenta possa ser utilizada como um importante e significativo recurso de ensino aprendizagem. Deve se ter um olhar crítico sobre a utilização de qualquer meio tecnológico para evitar que tais ferramentas tragam algum prejuízo para a aprendizagem, (MELONIO; FAÇANHA, 2018). A oferta de vídeos no YouTube é gigantesca, possui vídeos dinâmicos e estilos diferenciados porém temos que ter em mente que não será qualquer vídeo, tão pouco de qualquer forma a ser exposto para os alunos, que acarretará uma aprendizagem significativa, o vídeo só deve ser utilizado como estratégia de ensino quando for adequado, quando puder trazer conhecimento que faça sentido e que contemple as expectativas educacionais envolvidas (ARANHA et al, 2019). 
A facilidade de acesso e a introdução de vídeos trazem pontos positivos e negativos para o uso dessa mídia social. Em relação a pontos negativos destacamos a falta de privacidade dos usuários, pois qualquer pessoa pode filmar e postar vídeos no site, qualquer situação do dia a dia pode ser filmado e cair na rede, até mesmo filmagem de ruas, sendo visto e acessado por milhões de pessoas, inclusive de fora do Brasil. Além disso, não há respeito pelos direitos autorais, pois podemos encontrar na rede vários clipes, filmes e músicas que ali estão sem a autorização de seus produtores. Além de que, são encontradas exposições de menores de idade, informações enganosas, disseminação de preconceitos, imagens impróprias para menores, mensagens racistas, entre outros fatores (KAMERS, 2013).

Dentre tantos, destaca-se, também, como pontos positivos o descobrimento de novas culturas, a possibilidade de ter novos conceitos e aprendizados sobre assuntos diversos, como também, a liberdade de expressão (KAMERS, 2013).

Se tratando das notas atribuídas ao grau de satisfação pela colaboração da plataforma ao aprendizado dos educandos, as respostas foram às melhores possíveis. Também, porque, não tem como ficar insatisfeito, o site YouTube promoveu novos conceitos, aplicabilidades, trouxe novos modos de aprender, se comunicar e adquirir conhecimentos, para estes alunos. Antes o que era transmitido pelo YouTube nas salas de aulas, por alguns professores, no presente momento passou a ser adquirido no dia a dia, através de smartphones e outros aparelhos eletrônicos (BACELAR, 2018). O YouTube fora concebido diante da necessidade de assistir vídeos com maior facilidade, massificando-se ao longo dos anos, se tornando um dos principais meios de estudo online, tornou-se uma das maiores plataformas de estudo do mundo e um aliado crucial no processo de fortalecimento da relação ensino-aprendizagem, assim, tornando $O$ ato de aprender, buscar conhecimento e construção do saber mais prazeroso (BACELAR, 2018).

Outro fator relevante do nosso estudo, se deu pelo fato de $79,8 \%$ dos participantes concordam totalmente e 19,1\% concordam parcialmente com a integração de novas tecnologias no processo educacional. Tal concordância pela maioria deve-se compreender pela evolução das Novas Tecnologias de Informação e Comunicação 
(TICs). Hoje, no contexto globalizado que estamos inseridos se torna complicado pensar em educação sem nos conceder ao uso dessas inovações, pois trouxeram transformações significativas em vários aspectos sociais e educacionais, inclusive já observamos a inserção destas ferramentas nas práticas pedagógicas cotidianas (FERNANDES; NASCIMENTO, 2020). A utilização desses recursos deve ser assegurada e ofertada pelas instituições, pois essa inclusão apresenta grandes possibilidades aos educadores, proporcionando um ensino mais específico, originando mais autonomia e interação em diversos tipos de ensino e aprendizagem (FERNADES; NASCIMENTO, 2020).

O uso de tecnologias no processo educativo é super satisfatório, com elas o sistema educacional se torna muito mais democrático e competitivo, pelo nível de qualidade de informações que são processadas auxiliadas por essas inovações. Em cada instante se criam novos conhecimentos, proporcionando e potencializando o desenvolvimento do ensino-aprendizagem, favorecendo as instituições e as gerações futuras na sociedade. As novas tecnologias na educação além de serem de suma importância nos estudos, ajudam os alunos para o mercado de trabalho (SILVA, 2018).

\section{CONSIDERAÇÕES FINAIS}

Através dessa pesquisa, foi constatado que a plataforma YouTube é um excelente recurso pedagógico, que é bastante utilizada pelos estudantes, para estudar e fazer trabalhos acadêmicos. A grande maioria dos estudantes mencionou achar importante o uso deste recurso, pois devido à grande quantidade e variabilidade de conteúdos e informações gratuitas, fica bem mais fácil aprender, memorizar, revisar e aprofundar melhor os estudos, e assim entendem super bem o conteúdo.

Da mesma maneira, obtivemos resultados satisfatórios, por conta da maior parte dos discentes participantes terem relatado que já vivenciaram aulas com professores usando este Site, e que acham relevante e gostam quando o docente utiliza vídeos durante essas aulas. Além disso, opinaram que usufruir do YouTube traz contribuições 
para as suas aprendizagens, que estão satisfeitos com essa assistência e apoiam o emprego desta e de outras novas tecnologias no processo de ensino-aprendizagem.

Por conseguinte, concluímos que a utilidade desta e de outras tecnologias na educação têm se mostrado muito eficiente e vêm se solidificando dentro do cenário educacional atual, potencializando a busca do conhecimento e o desenvolvimento educacional.

\section{REFERÊNCIAS}

ALMEIDA, Ítalo, SILVA, Jeissy, JUNIOR, Sandoval, BORGES, Luzineide. Tecnologias e Educação: $O$ uso do YouTube na sala de aula, 2015. Disponível em:

https://www.editorarealize.com.br/revistas/conedu/trabalhos/TRABALHO_EV045_MD 1_SA4_ID8097_06092015214629.pdf . Acesso em: 09 de janeiro de 2020.

ARANHA, Carolina, SOUSA, Regina, JUNIOR, João, ROCHA, Juliana, SILVA, André. o YouTube como ferramenta educativa para o ensino de ciências, 2019. Disponível em: http://www.seer.ufu.br/index.php/olharesetrilhas/article/view/46164/25912 . Acesso em: 01 de setembro 2019.

BACELAR, Dandara. Educação e Inovação em Tecnologia: A Cultura Tecnológica com o Advento do YouTube como Ferramenta de Transmissão de Conteúdos Educacionais, 2018.

Disponível

em: https://www.nucleodoconhecimento.com.br/educacao/educacao-e-inovacao . Acesso em: 06 de fevereiro de 2020.

FERNANDES, Deise, NASCIMENTO, Cinara. A utilização das TICs na sala de atendimento educacional, $2019 . \quad$ Disponível em: https://www.nucleodoconhecimento.com.br/educacao/atendimentoeducacional?pdf=46846. Acesso em: 05 de fevereiro de 2020 . 
KAMERS, Nelito. O YouTube como ferramenta pedagógica no ensino de física, 2013.

http://www.faed.udesc.br/arquivos/id_submenu/151/nelito_jose_kamers.pdf . Acesso em: 05 de julho de 2019.

MELONIO, Ariane, MELONIO, Danielton, FAÇANHA, Luciano. O YouTube como ferramenta de ensino-aprendizagem, 2018. Disponível em: https://tecedu.pro.br/wpcontent/uploads/2018/11/Art3.Vol27-Ed.Tem\%C3\%A1ticalX-Nov-2018.pdf . Acesso em: 25 de agosto de 2019.

MORAN, José. O Uso das Novas Tecnologias da Informação e da Comunicação na EAD - uma leitura crítica dos meios, 1999. Disponível em: http://portal.mec.gov.br/seed/arquivos/pdf/T6\%20TextoMoran.pdf . Acesso em: 10 de janeiro de 2020.

MYCHALEYKO, Tatiana Rita. O vídeo como ferramenta pedagógica, 2015. Disponível em: https://www.lume.ufrgs.br/bitstream/handle/10183/133837/000982496.pdf?sequence $=1$ \&isAllowed=y. Acesso em: 25 de julho de 2019.

SCHMITT, Cleumara Maria. O YouTube como ferramenta pedagógica no ensino de Geografia, $2015 . \quad$ Disponível em: https://www.lume.ufrgs.br/bitstream/handle/10183/133982/000978838.pdf? sequence $=1$ \&isAllowed $=\mathrm{y}$. Acesso em: 25 de julho de 2019 .

SÉRIO, Ana Luiza, KAWAMURA, Maria Regina. Vídeos do YouTube como ferramenta de aprendizagem, 2014. Disponível em: http://www.sbf1.sbfisica.org.br/eventos/epef/xv/sys/resumos/T0368-1.pdf. Acesso em: 26 de julho de 2019.

SILVA, Claudio. A importância do uso das TICS na educação, 2018. Disponível em: https://www.nucleodoconhecimento.com.br/educacao/tics-na-educacao . Acesso em: 30 de junho de 2019 
SILVA, Marcelo José. A Linguagem Multimidiática do YouTube e o Ensino de Literatura, 2009.

Disponível

em:

http://artefactum.rafrom.com.br/index.php/artefactum/article/view/30. Acesso em 10 de agosto de 2019.

SOUSA, Caíque, LACERDA, Marlúcia, LIMA, Teresinha, 2017. Ensino de Biologia: - Jogo Didático como Estratégia Metodológica. Disponível em: https://www.nucleodoconhecimento.com.br/biologia/ensino-de-biologia?pdf=12982 . Acesso em: 20 de janeiro de 2020.

PECHANSKY, Rafaela. O YouTube como plataforma educacional: reflexões acerca do canal Me Salva Disponível em: http://www.portalintercom.org.br/anais/sul2016/resumos/R50-0123-1.pdf . Acesso em: 29 de junho de 2019.

PEREIRA, Marina. Uso do YouTube como ferramenta pedagógica, 2018. Disponível em: http://monografias.ice. ufjf.br/tcc-web/exibePdf?id=440 . Acesso em: 10 de janeiro de 2020.

PEREIRA, Maryana Barrêtto, SOUZA, Albano Goes, PEIXINHO, Kamilla Magalhães. A utilização da Internet como ferramenta de aprendizagem: o professor como inovador educacional, 2012.

Disponível em: http://educonse.com.br/2012/eixo_08/PDF/60.pdf . Acesso em: 26 de julho de 2019.

Brasil tem 126,9 milhões de pessoas conectadas: celular é o meio de acesso para 97\%. Nic.br. Disponível em: https://nic.br/noticia/na-midia/brasil-tem-126-9milhoes-de-pessoas-conectadas-celular-e-meio-de-acesso-para-97/ . Acesso em: 09 de janeiro de 2020.

TIC EDUCAÇÃO 2015 pesquisa sobre o uso das tecnologias de informação e comunicação nas escolas brasileiras. Cetic.br. Disponível em: https://cetic.br/media/docs/publicacoes/2/TIC_Edu_2015_LIVRO_ELETRONICO.pdf . Acesso em: 24 de julho de 2019. 
Enviado: Junho, 2020.

Aprovado: Agosto, 2020. 